
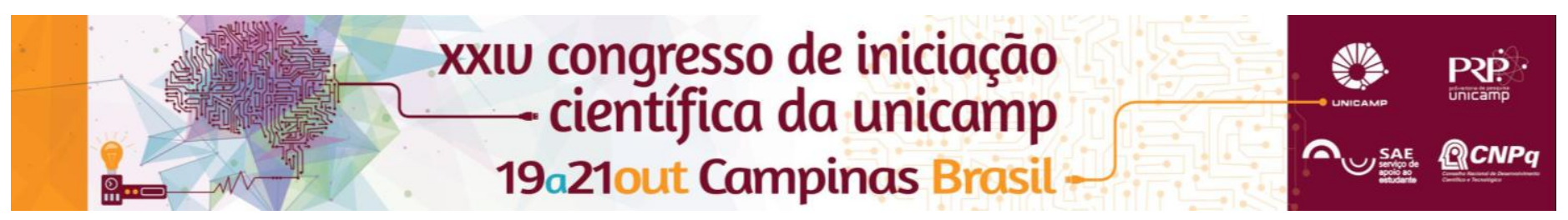

\title{
PROCEDIMENTOS ODONTOLÓGICOS REALIZADOS COM ANESTESIA GERAL EM PACIENTES COM NECESSIDADES ESPECIAIS
}

\author{
Maria Beatriz A. M. Saraiva*, Marcio A. Lopes
}

\section{Resumo}

O tratamento odontológico realizado com anestesia geral (AG) em ambiente hospitalar é necessário para pacientes especiais visto que não permitem a realização de procedimentos em consultório convencional com anestesia local. Essa modalidade de tratamento é indicada para pacientes não colaborativos e inclui principalmente pacientes com paralisia cerebral, síndrome de Down, autismo, deficiência mental, entre outras.

\section{Palavras-chave:}

Anestesia geral, pacientes especiais, tratamento odontológico

\section{Introdução}

Os pacientes especiais em sua maioria apresentam dificuldade em manter uma saúde bucal adequada e ter acesso ao serviço odontológico. Com isso, o uso da anestesia geral é uma alternativa que permite realizar o tratamento odontológico (1).

Além das dificuldades para intervenção odontológica e para higienização bucal adequada, estes pacientes podem apresentar alterações na quantidade e qualidade da saliva, ter uma dieta mais cariogênica (2).

O objetivo deste estudo foi descrever os procedimentos odontológicos que foram realizados com anestesia geral em pacientes com necessidades especiais do Orocentro da FOP- UNICAMP.

\section{Resultados e Discussão}

No levantamento feito para o trabalho foram analisados 200 prontuários, obtendo-se então 87 pacientes que preenchiam os critérios de inclusão. Com relação a doença base, a maioria dos pacientes tinham Paralisia Cerebral correspondendo a 24 pacientes $(27,58 \%)$, seguido por Deficiência Mental com 20 pacientes (22,98\%).

O maior número de encaminhamentos se deu por Hospital/Posto de saúde correspondendo a $27,58 \%$. O motivo desses encaminhamentos para o Orocentro foi em $59,77 \%$ dos casos por ser o paciente classificado como especial e $25,28 \%$ por já ser diagnosticado da necessidade do uso de anestesia geral.

Dos 87 pacientes atendidos no Orocentro, 50 necessitaram de anestesia geral $(57,48 \%)$. Por outro lado, 19 pacientes conseguiram realizar tratamento com anestesia local (21,84\%) (Fig 1). Desses 50 pacientes atendidos com anestesia geral, 32 pacientes (64\%) estavam com os prontuários completos e apresentavam em sua maioria a realização de procedimentos de periodontia e cirurgia (exodontia) (46,87\%) (Fig 2). Por outro lado, 18 pacientes (36\%), não tinham informações nos prontuários.

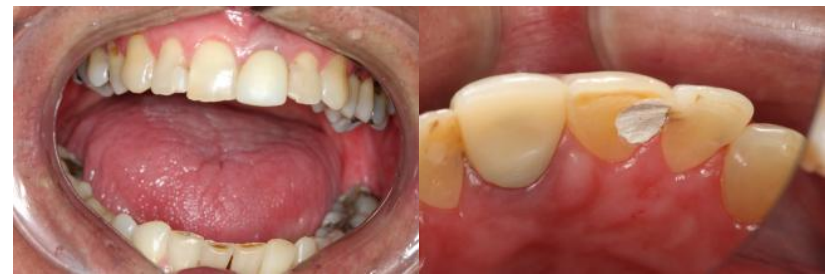

Fig 1. (A) - Paciente com Paralisia Cerebral mostrando dentes anteriores.(B) - Restauração provisória em dente anterior.

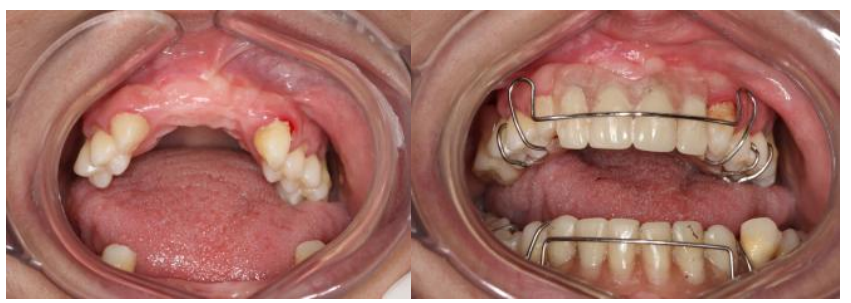

Fig 2. (A) - Paciente com Síndrome de Down com ausência dos dentes superiores anteriores (B) - Paciente com prótese (aparelho mantenedor de espaço).

\section{Conclusões}

Observamos com o presente estudo que a anestesia geral é uma alternativa importante para manejo odontológico de pacientes como necessidades especiais, sendo procedimentos de periodontia, dentística e cirurgia (exodontia) os mais realizados. Por outro lado, mesmo com dificuldades motoras e condições sistêmicas debilitadas, nem sempre o paciente especial será encaminhado para $A G$, podendo ser atendido em ambulatório.

(1)FERGUSON FS, BERENTSEN B, RICHARDSON PS. Dentists' willingness to provide care for patients with developmental disabilities. Speec Care Dentist 1991,11: 234-7.

(2)CONASS. Conselho Nacional de Secretários de Saúde. Atenção Primária e Promoção da Saúde. Conselho Nacional de Secretários de Saúde. 